\title{
Case Files of the California Poison Control System, San Francisco Division: Blue Thunder Ingestion: Methanol, Nitromethane, and Elevated Creatinine
}

\author{
Adeline Su-Yin Ngo $\cdot$ Freda Rowley $\cdot$ Kent R. Olson
}

Published online: 30 March 2010

(C) The Author(s) 2010. This article is published with open access at Springerlink.com

Keywords Nitromethane $\cdot$ Methanol Creatinine

\section{Case Presentation}

A 41-year-old man with a history of ethanol abuse was found on the streets with his clothing saturated with fecal material. In the emergency department (ED), he was confused and had an unsteady gait. He was sleepy and slow in responding, although easily arousable. He admitted to being depressed and said that he tried to commit suicide by consuming vodka and "Blue Thunder", a fuel for radiocontrolled racing cars that he had purchased from a hobby shop the day before presentation. He denied any other drug ingestion or previous medical history and was not taking any medications. He did not have any focal neurological symptoms, visual disturbance, gastrointestinal symptoms such as nausea or vomiting, or chest discomfort.

His vital signs were within normal limits: temperature $36.4^{\circ} \mathrm{C}$, blood pressure $145 / 87 \mathrm{~mm} \mathrm{Hg}$, heart rate $95 / \mathrm{min}$, respiratory rate $16 / \mathrm{min}$ and pulse oximetry saturation $97 \%$ on room air. His physical examination was unremarkable except for an unsteady gait. His cranial nerves, motor, and sensory findings were grossly intact. As he had attempted to leave the ED several times despite being ataxic, he was

This case was not previously presented in any meetings or in abstract form.

A. S.-Y. Ngo $(\bowtie) \cdot$ F. Rowley $\cdot$ K. R. Olson

California Poison Control System, San Francisco Division,

University of California,

2789 25th Street, Suite 2022,

San Francisco, CA 94110, USA

e-mail: angosy@gmail.com placed in restraints and sedated with intravenous boluses of lorazepam and admitted for further workup.

Computed tomography of his brain did not show any gross abnormalities. Initial laboratory data included: sodium $135 \mathrm{mmol} / \mathrm{L}$, potassium $3.8 \mathrm{mmol} / \mathrm{L}$, chloride $97 \mathrm{mmol} / \mathrm{L}$, bicarbonate $21 \mathrm{mmol} / \mathrm{L}$, blood urea nitrogen $7.9 \mathrm{mmol} / \mathrm{L}$ $(22.0 \mathrm{mg} / \mathrm{dL})$, creatinine $8,270 \mu \mathrm{mol} / \mathrm{L}(93.6 \mathrm{mg} / \mathrm{dL})$, and glucose $6.5 \mathrm{mmol} / \mathrm{L}(117 \mathrm{mg} / \mathrm{dL})$. The anion gap was $17 \mathrm{mmol} / \mathrm{L}$. Lactic acid and hepatic enzymes were within normal limits. The serum ethanol, acetaminophen, and salicylate levels were below detection limits. Urinalysis was normal with a pH of 5.5. Serum samples were referred to an outside laboratory for methanol, ethylene glycol, acetone, isopropyl alcohol, and paraldehyde levels. After $4 \mathrm{~h}$ of supportive treatment including intravenous fluids, repeat laboratory results were: sodium $134 \mathrm{mmol} / \mathrm{L}$, potassium $3.8 \mathrm{mmol} / \mathrm{L}$, chloride $98 \mathrm{mmol} / \mathrm{L}$, bicarbonate $23 \mathrm{mmol} / \mathrm{L}$, blood urea nitrogen $6.9 \mathrm{mmol} / \mathrm{L}(19.0 \mathrm{mg} / \mathrm{dL})$, and glucose $6.5 \mathrm{mmol} / \mathrm{L}(117 \mathrm{mg} / \mathrm{dL})$.

The laboratory had independently decided that nitromethane was an interfering substance and did not repeat the creatinine level. The anion gap was now $13 \mathrm{mmol} / \mathrm{L}$ and the calculated osmolality [1] was $282 \mathrm{mmol} / \mathrm{kg}$. Serum osmolality determined by freezing point depression was $430 \mathrm{mmol} / \mathrm{kg}$ (reference range $275-295 \mathrm{mmol} / \mathrm{kg}$ ). The osmolar gap was estimated to be $148 \mathrm{mmol} / \mathrm{kg}$.

Is this Patient's Presentation Consistent with Methanol Poisoning?

After ingestion, the hepatic enzyme alcohol dehydrogenase converts methanol to formaldehyde, which is then converted to formic acid by formaldehyde dehydrogenase [2]. Although formaldehyde is more toxic than formic acid, it 
does not accumulate during poisoning on account of its short half-life of about $1.5 \mathrm{~min}$ [3, 4]. Formic acid, an inhibitor of cytochrome oxidases $\mathrm{c}$ and aa3, primarily contributes to the toxic sequelae of methanol poisoning, including ocular toxicity and the fall in plasma bicarbonate concentration and consequent increase in anion gap [5]. Ocular toxicity essentially identical to that produced in methanol poisoning has been described after formate administration in animals [4]. Also, results suggest that formaldehyde is not a major factor in the toxic syndrome produced by methanol [6]. The clinical manifestations of methanol ingestion include headache, dizziness, nausea, vomiting, weakness, and epigastric pain, as well as developing an elevated anion gap acidosis. The severity of symptoms secondary to methanol poisoning appears to correlate with the degree of metabolic acidosis [7, 8]. Mortality correlates with the severity of acidosis and the formate concentration rather than with serum methanol concentration [9].

Although metabolic acidosis is a characteristic feature of methanol poisoning, its onset may be delayed for 18-24 h, or even longer (up to $72 \mathrm{~h} \mathrm{[10])} \mathrm{with} \mathrm{concurrent} \mathrm{ethanol}$ ingestion [11-16], due to competition for the enzyme alcohol dehydrogenase. Thus, the patient may be relatively asymptomatic during the latent period [17]. Our patient had no measurable ethanol level, yet his acidosis was very mild with an anion gap of only $17 \mathrm{mmol} / \mathrm{L}$ and a bicarbonate level of $21 \mathrm{mmol} / \mathrm{L}$. A significant anion gap may not be present early in the course of methanol intoxication. In a review of 113 acute methanol exposures reported to a poison center, metabolic acidosis was reported in only 26 cases (23\%) [18]. Therefore, the absence of acidosis does not rule out methanol ingestion.

Possible reasons for our patient not developing worsening or severe acidosis may include an inaccurate history of ingestion. He might have ingested only a small amount of methanol, or ingested it shortly before being found. He may also have co-ingested ethanol or other types of alcohols that are metabolized by alcohol dehydrogenase, such that the metabolism of methanol to formate was blocked. Such other alcohols might include ethylene glycol or isopropanol. However, ethanol was not detected and there was no nail polish remover-like odor detected in the patient, which would be present when isopropyl alcohol is metabolized to acetone. There was improvement in our patient's anion-gap acidosis simply with hydration, which also argues against ethylene glycol and methanol ingestions.

Thus, even though our patient currently appears relatively well, it is possible that he ingested methanol. It would be prudent to manage him as for methanol ingestion, given the history of ingestion and the very large osmolal gap. Nevertheless, it is unusual that our patient's anion gap and acidosis improved in the short duration of supportive management with intravenous fluids alone.
What is Nitromethane and What is its Toxicity?

Nitromethane is a popular solvent in organic and electroanalytical chemistry [19]. It is also used as a fuel in racing, particularly drag racing, to enhance combustion [20]. The oxygen content of nitromethane enables it to burn with much less atmospheric oxygen in comparison to hydrocarbons such as gasoline. In model aircraft and remotecontrolled car fuels such as "Blue Thunder", the primary ingredient is generally methanol with some nitromethane (up to $65 \%$, but rarely over $30 \%$ since nitromethane is expensive compared to methanol) and 10-20\% lubricants (usually castor oil or a synthetic oil). During combustion, this fuel produces a characteristic blue smoke [20]. Nitromethane is highly lipid soluble, and acute exposures tend to be inadvertent dermal or ocular exposures which generally result in local irritation but no apparent sequelae [21]. The American Conference of Governmental Industrial Hygienists lists the adverse health effects of nitromethane as including dermal irritation, central nervous system depression, liver and thyroid toxicity, blood dyscrasias, and neuropathy [22].

Following acute inhalational exposure, animal studies suggest a relatively low toxicity of nitromethane [23, 24]. Rats and mice were exposed to nitromethane at a variety of concentrations for $6 \mathrm{~h}$ per day, 5 days per week, from 16 days to 2 years. In the 16-day study of rats, all those exposed to $1,500 \mathrm{ppm}$ showed loss of coordination in the hindlimbs. Sciatic nerve degeneration was found in all rats exposed to $375 \mathrm{ppm}$ and above. In the 13-week study, hindlimb paralysis was seen in all rats in the 1,500-ppm group. Rats exposed to $375 \mathrm{ppm}$ of nitromethane or greater had minimal to mild degeneration of the spinal cord and sciatic nerve. In contrast, mice demonstrated no neurologic abnormalities in any of the studies [25]. Unfortunately, oral toxicity data in animals is limited.

In a human case report, a 20 -year-old woman who had worked for 2 years using a mixture of trichlorotrifluoroethane (94\%), methanol (6\%), and nitromethane $(0.25 \%)$ developed Parkinsonism in the absence of other potential etiologies [26]. The authors concluded that exposure to nitromethane could have been the cause of the Parkinsonism. A 19-year-old man developed a primary, symmetric demyelinating polyneuropathy after a 2-month exposure to an industrial solvent composed primarily of 1-bromopropane, but also containing nitromethane and other components [27]. The authors attributed the neuropathy to the 1-bromopropane exposure.

The limited acute toxicity of nitromethane suggests that exposures require only supportive care with no specific therapy [21]. Although different racing car fuels contain varying concentrations of nitromethane and methanol, management of this mixed poisoning should focus on the appropriate treatment for methanol toxicity. 
Why is There a False Elevation of Creatinine with Nitromethane?

Nitromethane cause spurious elevations of the serum creatinine when the Jaffe colorimetric method is used to determine serum creatinine concentration [28-33]. This method involves injecting a sample of the patient's serum into an alkaline picrate solution. Creatinine in the sample combines with alkaline picrate to form a red-colored complex or chromophore, the light absorbance of which can then be measured in the 470-550 $\mathrm{nm}$ range using a double-beam spectrophotometer. The rate of absorbance is directly proportional to the creatinine concentration in the serum [29]. Nitromethane also forms a red chromophore with alkaline picrate with an absorbance similar to that of the creatininepicrate chromophore [30]. Thus, when nitromethane is present in a patient's serum, the reaction of both creatinine and nitromethane with alkaline picrate can result in a significantly but spuriously elevated creatinine concentration [33].

Can the Degree of Cross-reactivity Predict the Nitromethane Level?

There is a linear relationship between the concentration of nitromethane and the rise in serum creatinine concentration measured by the Jaffe method [21, 28]. This correlation could provide a surrogate marker for significant methanol exposure in those who ingest racing car fuel [32]. Analysis by leastsquares linear regression of ten serum samples containing nitromethane showed the following relationship [29]:

Apparent [creatinine, $\mathrm{mmol} / \mathrm{L}$ ]

$$
=0.99[\text { nitromethane, } \mathrm{mmol} / \mathrm{L}]+0.21( \pm 0.013)
$$

Using this equation in our patient, with a creatinine of $8,270 \mu \mathrm{mol} / \mathrm{L}(93.6 \mathrm{mg} / \mathrm{dl})$, we estimated a nitromethane level of approximately $8 \mathrm{mmol} / \mathrm{L}$ :

1. Apparent (creatinine, $\mathrm{mmol} / \mathrm{L}$ ) $=0.99$ (nitromethane, $\mathrm{mmol} / \mathrm{L})+0.21( \pm 0.013)$

2. $8.27 \mathrm{mmol} / \mathrm{L}=0.99$ (nitromethane, $\mathrm{mmol} / \mathrm{L}$ ) +0.21 $( \pm 0.013)$

3 . $($ Nitromethane $)=(8.27-0.21( \pm 0.013)) / 0.99=8.13-$ $8.15 \mathrm{mmol} / \mathrm{L}$

A nitromethane level of $8 \mathrm{mmol} / \mathrm{L}$ would be expected to contribute only about eight to the osmol gap, leaving a residual, unexplained osmol gap of about 140. Assuming the remaining osmol gap is due to methanol alone, the estimated serum methanol level would be around $400 \mathrm{mg} / \mathrm{dL}$, if multiplied by a conversion factor of 3.2 (one-tenth the molecular weight of methanol) [34].

The fatal oral dose of methanol is estimated to be 30 $240 \mathrm{~mL}(20-150 \mathrm{~g})$. The minimum toxic dose is approxi- mately $100 \mathrm{mg} / \mathrm{kg}$ [35]. Serum methanol concentrations greater than $20 \mathrm{mg} / \mathrm{dL}(>6.24 \mathrm{mmol} / \mathrm{L})$ are considered potentially toxic [36], and concentrations of greater than $40 \mathrm{mg} / \mathrm{dL}(>12.4 \mathrm{mmol} / \mathrm{L})$ can be fatal, but individual sensitivity varies [37]. Based on these estimated levels, and without the benefit of a rapid analysis for methanol, it was decided that our patient had ingested a significant amount of methanol and he was initially treated with a loading dose of $15 \mathrm{mg} / \mathrm{kg}$ intravenous fomepizole and 2 hours of hemodialysis.

\section{Are There Other Causes of a Falsely Elevated Serum} Creatinine Level?

The concentration of creatinine in serum is the most widely used and commonly accepted measure of renal function in clinical medicine. In renal failure, deterioration of renal function, results in the accumulation of nitrogenous waste products, including creatinine [38].

In the absence of renal failure, elevated creatinine levels may be due to factors influencing creatine production as well as elimination. The total muscle mass is the most important determinant of the creatine pool size and thereby of creatinine production [39]. Hence serum creatinine is increased in people with increased muscle mass, those with a high-meat diet, users of anabolic steroids, and weight lifters [38]. Trauma or febrile states have been associated with significant increases in the excretion of creatinine [40-43].

Rhabdomyolysis or extensive crush injury may result in an increase of serum creatinine, at times exceeding what can be accounted for by the decrement in renal function [44], the excess creatinine is generally assumed to derive from injured muscle. But it was found that phosphocreatine was present in muscle in sufficient amounts to serve as a direct intermediate in the conversion of phosphocreatine to creatinine [45].

Other substances that can cause false elevations of the measured serum creatinine determined by the Jaffe method include ketoacids, acetone, pyruvate, glucose, uric acid, proteins, creatine, ascorbic acid, dopamine, and certain cephalosporins [46, 47]. High concentrations of bilirubin can falsely lower the serum creatinine concentration determined by the Jaffe method [46, 47]. Enzymatic methods for determining serum creatinine concentration are not affected by the presence of nitromethane in serum [21, 30, 47]. Substances that can interfere with this enzymatic method when present in the serum include creatine, bilirubin, dopamine, dobutamine, ascorbic acid, and calcium dobesilate [38, 46, 47].

What are Some Other Common Laboratory Analysis Cross-reactivities of Interest to Toxicologists?

The techniques for detecting the presence of drugs include a variety of chromatographic methods, immunoassays, and chemical and spectrometric techniques. A number of 
Table 1 Examples of false-positive results in toxicology testing

\begin{tabular}{ll}
\hline $\begin{array}{l}\text { Drug } \\
\text { Amphetamines (urine) }\end{array}$ & $\begin{array}{l}\text { Some reported cause(s) of a false positive result } \\
\text { Cross-reacting stimulant drugs (MDMA, pseudoephedrine, etc.); cross-reacting non-stimulant drugs } \\
\text { (bupropion, labetalol, ranitidine, sertraline, and trazodone); drugs metabolized to amphetamines } \\
\text { (benzphetamine, selegiline) }\end{array}$ \\
Ethylene glycol & Other glycols; elevated triglycerides \\
Lithium & Use of a green-top Vacutainer specimen tube (contains lithium heparin, may raise Li level by 6-8 mEq/L) \\
Methadone (urine) & Diphenhydramine, verapamil \\
Opiates (urine) & May be triggered by ingestion of poppy seeds. \\
Osmolality & Use of a gray-top Vacutainer specimen tube (contains fluoride-oxalate) can raise measured osmolality by up \\
Phencyclidine (urine) & to 150 mOsm/kg \\
Tricyclic antidepressants & Diphenhydramine, dextromethorphan, venlafaxine
\end{tabular}

Adapted from Osterloh J and Haller CA, “Toxicology Testing," in Poisoning and Drug Overdose, 5th edition, McGraw-Hill, 2007, pp. 43-44

interferences resulting in "false-positive" results have been reported [48]. Some common, important interferences resulting in false-positive results are listed in Table 1.

\section{Case Continuation}

Based on the history of ingestion of "Blue Thunder" fuel which may contain varying amounts of methanol (43-77\%) and nitromethane (5-35\%) and the presence of a large osmolal gap even after accounting for the contribution of the nitromethane, we recommended treatment with fomepizole, thiamine (the patient was suspected to be an alcoholic), folate, and transfer to a facility with dialysis capabilities.

Two days later, the reference laboratory that the patient's serum was sent out to reported the initial serum methanol concentration to be $399 \mathrm{mg} / \mathrm{dL}$ (124 mmol/L). The methanol concentration decreased to $47 \mathrm{mg} / \mathrm{dL}(1.47 \mathrm{mmol} / \mathrm{L})$ approximately after completing $2 \mathrm{~h}$ after dialysis, while the apparent creatinine concentration decreased to $66.8 \mathrm{mg} / \mathrm{dL}$. Ethylene glycol, acetone, isopropyl alcohol, acetaldehyde, and paraldehyde were not detected in the initial serum specimen. The patient continued to have daily dialysis (approximately $19 \mathrm{~h}$ of dialysis in total) until the osmolal gap narrowed and his apparent creatinine level was reduced to $168 \mu \mathrm{mol} / \mathrm{L}(1.9 \mathrm{mg} / \mathrm{dL})$. He was also treated orally with folic acid $1 \mathrm{mg}$, thiamine $100 \mathrm{mg}$, and a multivitamin daily. Although the patient had no visual disturbances or any significant metabolic acidosis, he had auditory hallucinations thought to be related to alcohol withdrawal, which was treated with benzodiazepines. He was discharged to a psychiatric facility after 9 days of hospitalization.

\section{Conclusion}

Toy racing car and other nitromethane-containing fuel additives often contain significant concentrations of metha- nol. Unfortunately, most hospitals are not able to perform a rapid quantitative test for methanol. In addition, nitromethane causes a marked false elevation of the serum creatinine level when measured by the Jaffe method, which can be exploited to estimate the nitromethane level. If the relative concentrations of nitromethane and methanol in the fuel are known, then the estimated methanol level can be extrapolated. If the relative concentrations are not known, the nitromethane level can be subtracted from the osmolal gap to provide a residual estimate of the methanol level. Based on the extrapolated methanol level, appropriate treatment with fomepizole and hemodialysis can be recommended.

Acknowledgments There is no financial funding or conflicts of interest for this project.

Open Access This article is distributed under the terms of the Creative Commons Attribution Noncommercial License which permits any noncommercial use, distribution, and reproduction in any medium, provided the original author(s) and source are credited.

\section{References}

1. Khajuria A, Krahn J (2005) Osmolality revisited: deriving and validating the best formula for calculated osmolality. Clin Biochem 38:514-519

2. Brent J, McMartin K, Phillips S, Aaron C, Kulig K, Methylpyrazole for Toxic Alcohols Study Group (2001) Fomepizole for the treatment of methanol poisoning. N Engl J Med 344(6):424-429

3. Burkhart KK, Kulig KW (1990) The other alcohols: Methanol, ethylene glycol, and isopropranol. Emerg Med Clin North Am 8:913-928

4. McMartin KE, Martin-Amat G, Noker PE et al (1979) Lack of a role for formaldehyde in methanol poisoning in the monkey. Biochem Pharmacol 28:645-649

5. Palmisano J, Gruver C, Adams ND (1987) Absence of anion gap metabolic acidosis in severe methanol poisoning: a case report and review of the literature. Am J Kidney Dis 9:441-444

6. McMartin KE, Ambre JJ, Tephly TR (1980) Methanol poisoning in human subjects: role for formic acid accumulation in the metabolic acidosis. Am J Med 68:414-418 
7. Liu JJ, Daya MR, Carrasquillo O (1998) Prognostic factors in patients with methanol poisoning. Clin Toxicol 36:175-181

8. Hovda KE, Hunderi OH, Rudberg N (2004) Anion and osmolal gaps in the diagnosis of methanol poisoning: clinical study in 28 patients. Intensive Care Med 30:1842-1846

9. Barceloux DG, Bond GR, Krenzelok EP, Cooper H, Vale JA, American Academy of Clinical Toxicology Ad Hoc Committee on the Treatment Guidelines for Methanol Poisoning (2002) American Academy of Clinical Toxicology practice guidelines on the treatment of methanol poisoning. J Toxicol Clin Toxicol 40(4):415-446

10. Bennett IL, Cary FH, Mitchell GL, Cooper MN (1953) Acute methyl alcohol poisoning: a review based on experiences in an outbreak of 323 cases. Medicine (Baltimore) 32(4):431-463

11. Bitar ZI, Ashbu SD, Ahmed S (2004) Methanol poisoning: diagnosis and management. A case report. Int J Clin Pract 58:1042-1044

12. Hantson Ph, Moniotte S, Moulin P (2002) Is heart donation possible after fatal methanol poisoning? J Toxicol Clin Toxicol 40 (3):372

13. Radam M, Hamza A, Landgraf B (2002) Successful multiorgan transplant after donors death caused by suicidal methanol ingestion. J Toxicol Clin Toxicol 40(3):373-374

14. Polak WG, Chudoba P, Patrzalek D (2002) Methanol-intoxicated donors: an acceptable source of organs. Transplant Proc 34:2569-2570

15. Girault C, Tamion F, Moritz F (1999) Fomepizole (4-methylpyrazole) in fatal methanol poisoning with early CT scan cerebral lesions. J Toxicol Clin Toxicol 37:777-780

16. Jacobsen D, Bredesen JE, Eide I (1982) Anion and osmolal gaps in the diagnosis of methanol and ethylene glycol poisoning. Acta Med Scand 212:17-20

17. Gonda A, Gault H, Churchill D (1978) Hemodialysis for methanol intoxication. Am J Med 64:749-758

18. Kalkan S, Cevik AA, Cavdar C, Aygoren O, Akgun A, Ergun N, Tuncok Y (2003) Acute methanol poisonings reported to the Drug and Poison Information Center in Izmir, Turkey. Vet Hum Toxicol 45(6):334-337

19. Coetzee JF, Chang TH (1986) Recommended methods for the purification of solvents and tests for impurities: nitromethane. Pure Appl Chem 58:1541-1545

20. Ma H, Kar K, Stone R, Raine R, Thorwarth H (2005) Analysis of combustion in a small homogeneous charge compression assisted ignition engine. Int J Engine Res 7:237-253

21. Mullins ME, Hammett-Stabler CA (1998) Intoxications with nitromethane-containing fuels: don't be "fueled" by the creatinine. J Toxicol Clin Toxicol 36:315-320

22. Page EH, Pajeau AK, Arnold TC, Fincher AR, Goddard MJ (2001) Peripheral neuropathy in workers exposed to nitromethane. Am J Ind Med 40:107-113

23. Machle W, Scott EW, Treon JF (1940) The physiological response of animals to some simple mononitroparaffins and to certain derivatives of these compounds. J Ind Hyg Toxicol 22:315-332

24. Dayal R, Gescher A, Harpur ES, Pratt I, Chipman JK (1989) Comparison of the hepatotoxicity in mice and the mutagenicity of three nitroalkanes. Fundam Appl Toxicol 13:341-348

25. (1997) Toxicology and carcinogenicity studies of nitromethane (CAS No. 75-52-5) in F344/N rats and B6C3F1 mice (inhalation studies). Government reports announcements and index, National Toxicology Program (NTP), p 23

26. Sandyk R, Gillman MA (1984) Motor dysfunction following chronic exposure to a fluoroalkane solvent mixture containing nitromethane. Eur Neurol 23:479-481
27. Sclar G (1999) Encephalomyeloradiculopathy following exposure to an industrial solvent. Clin Neurol Neurosurg 101(3):199-202

28. Gabrielli A, Hammett-Stabler CA (1998) False elevation of serum creatinine following skin absorption of nitromethane complicates the clinical diagnosis of rhabdomyolysis. Chest 113:1419-1422

29. De Leacy EA, Brown NN, Clague AE (1989) Nitromethane interferes in assay of creatinine by the Jaffe reaction. Clin Chem 35:1772-1774

30. Booth CJ, Naidoo D, Rosenberg AR, Kainer G (1999) Elevated creatinine after ingestion of model aviation fuel: interference with the Jaffe reaction by nitromethane. J Paediatr Child Health 35:503-504

31. Janzen IE, Dossetor JF, Seem CP (2005) Model car fuel poisoning. Ann Clin Biochem 42:308-309

32. Mell HK, Lintner CP, Sztajnkrycer MD (2005) Artifactually elevated serum creatinine determination after nitromethane ingestion (abstract). Clin Toxicol 43:660-661

33. Cook MD, Clark RF (2007) Creatinine elevation associated with nitromethane exposure: a marker of potential methanol toxicity. $\mathrm{J}$ Emerg Med 33(3):249-253

34. (2007) Table I-22. In: Olson KR (ed) Poisoning and drug overdose, 5th edn. Lange Medical Books/McGraw-Hill, New York, p 32

35. Anderson IB (2007) Methanol. In: Olson KR (ed) Poisoning and drug overdose, 5th edn. Lange Medical Books/McGraw-Hill, New York, pp 260-262

36. Kostic MA, Dart RC (2003) Rethinking the toxic methanol level. J Toxicol Clin Toxicol 41(6):793-800

37. Kahn A, Blum D (1979) Methyl alcohol poisoning in an 8-monthold boy: an unusual route of intoxication. J Pediatr 94:841-843

38. Perrone RD, Madias NE, Levey AS (1992) Serum creatinine as an index of renal function: new insights into old concepts. Clin Chem 38:1933-1953

39. Heymsfield SB, McManus C, Smith J et al (1982) Anthropometric measurement of muscle mass: revised equations for calculating bone-free arm muscle area. Am J Clin Nutr 36:680-690

40. Frawley JP, Artz CP, Howard JM (1955) Muscle metabolism and catabolism in combat casualties. Arch Surg 71:612-616

41. Schiller WR, Long CL, Blakemore WS (1979) Creatinine and nitrogen excretion in seriously ill and injured patients. Surg Gynecol Obstet 149:561-566

42. Long CL, Birkhahn RH, Geiger JW (1981) Urinary excretion of 3-methylhistidine: an assessment of muscle protein metabolism in adult normal subjects and during malnutrition, sepsis, and skeletal trauma. Metabolism 30:765-776

43. Threlfall CJ, Stoner HM, Galasko CSB (1981) Patterns in the excretion of muscle markers alter trauma and orthopedic surgery. $\mathrm{J}$ Trauma 21:140-147

44. Rudnick ME, Bastl CP, Elfinbein IB et al (1983) The differential diagnosis of acute renal failure. In: Brenner BM, Lazarus JM (eds) Acute renal failure. WB Saunders, Philadelphia, pp 176-222

45. Iyengar ME, Coleman DW, Butler TM (1985) Phosphocreatinine, a high-energy phosphate in muscle, spontaneously forms phosphocreatine and creatiine under physiological conditions. J Biol Chem 260:7562-7567

46. Weber JA, Van Zanten AP (1991) Interferences in current methods for measurements of creatinine. Clin Chem 37:695-700

47. Daly TM, Kempe KC, Scott MG (1996) "Bouncing" creatinine levels. N Engl J Med 334:1749-1750

48. Osterloh JD (2001) Laboratory testing in emergency toxicology. In: Ford MD (ed) Clinical toxicology. W.B. Saunders Company, Philadelphia, pp 51-60 